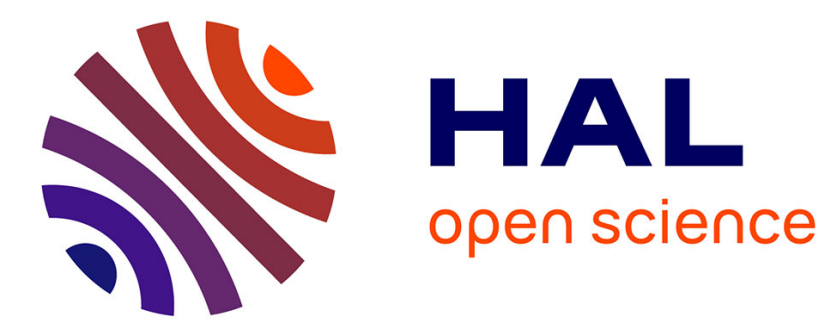

\title{
More perceived but not faster evolution of heat stress than temperature extremes in the future
}

\author{
Audrey Brouillet, Sylvie Joussaume
}

\section{To cite this version:}

Audrey Brouillet, Sylvie Joussaume. More perceived but not faster evolution of heat stress than temperature extremes in the future. Climatic Change, 2020, 162 (2), pp.527-544. 10.1007/s10584020-02752-z . hal-02967346

\section{HAL Id: hal-02967346 \\ https://hal.science/hal-02967346}

Submitted on 6 Jan 2021

HAL is a multi-disciplinary open access archive for the deposit and dissemination of scientific research documents, whether they are published or not. The documents may come from teaching and research institutions in France or abroad, or from public or private research centers.
L'archive ouverte pluridisciplinaire HAL, est destinée au dépôt et à la diffusion de documents scientifiques de niveau recherche, publiés ou non, émanant des établissements d'enseignement et de recherche français ou étrangers, des laboratoires publics ou privés. 


\title{
More perceived but not faster evolution of heat stress than temperature extremes in the future
}

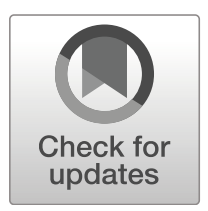

\author{
Audrey Brouillet $^{1}\left[\right.$ [D . Sylvie Joussaume ${ }^{1}$
}

Received: 5 January 2020 / Accepted: 20 May 2020 / Published online: 28 July 2020

(C) The Author(s) 2020

\begin{abstract}
Global warming is projected to intensify during the twenty-first century. Yet, only few studies investigate how global warming could be perceived by future populations. Here, we propose an assessment of how climate change could be perceived by combining climatological indicators. We analyse extremes of temperature $\left(T_{99}\right)$ and simplified Wet-Bulb Globe Temperature (WBGT 99 ), a heat stress index assessing the combined effect of elevated temperature and humidity on the human body. The speed of change is defined for each year as the difference between the previous 20 years and the twenty upcoming years (i.e. with a moving baseline), and we assess how these speeds emerge from each last 20year interannual variability. Using a set of 12 CMIP5 models, speeds of change of $T_{99}$ and WBGT $_{99}$ in 2080 are both twice as fast compared with current speeds in mid-latitudes, and by up to four times faster in the tropics under the RCP8.5 scenario. Warming accelerations are thus similar for $T_{99}$ and $\mathrm{WBGT}_{99}$. However, these speeds in tropical regions in 2080 are projected to be 2.3 times larger than the last 20-year interannual variability for $\mathrm{WBGT}_{99}$, and only 1.5 to 1.8 times larger for $T_{99}$. According to the models, the WBGT $_{99}$ intensification will be more emergent from the recent year-to-year variability than the $T_{99}$ warming. This analysis suggests that the accelerated warming of heat extremes will be felt more strongly by populations than current changes for RCP8.5, and that this evolution will be more perceived in heat stress than in temperature, particularly within the tropics.
\end{abstract}

Keywords Extremes $\cdot$ Heat stress $\cdot$ Temperature $\cdot$ Speed of change Global warming · Climate models

Electronic supplementary material The online version of this article (https://doi.org/10.1007/s10584-020-02752-z) contains supplementary material, which is available to authorized users.

Audrey Brouillet

audrey.brouillet@1sce.ipsl.fr

1 Laboratoire des Sciences du Climat et de l'Environnement (LSCE-IPSL), CEA/CNRS/UVSQ, 91191, Gif-sur-Yvette, France 


\section{Introduction}

A recent and unprecedented warming of the atmosphere and oceans has been exhibited in many studies (Hartmann et al. 2013). This global warming mainly results from the increased levels of greenhouse gases induced by anthropogenic activities. General circulation models (GCMs) project a continuous warming during the twenty-first century under the high baseline emission RCP8.5 scenario, and a "peak-and-decline" warming with the mitigation RCP2.6 pathway (van Vuuren et al. 2011). Models simulate a larger future mean warming over land than over oceans (Collins et al. 2013).

According to GCMs, this mean change and a preferential warming of the hot tail of temperature distributions both lead to an increase in amplitude, frequency and duration of warm extremes over land (e.g. Meehl 2004; Alexander et al. 2006), that may induce major concerns for society, economy and health impacts (Orlowsky and Seneviratne 2012). The consequent heat stress, the well-established effect of temperature and humidity on human health, is projected to intensify in the future, strongly increasing health risks for populations (Kjellstrom et al. 2009) and decreasing labour capacity (Dunne et al. 2013). Despite a greater warming in northern mid-latitudes, tropical and subtropical areas are projected to experience the largest intensification of heat stress extremes, due to the higher combined temperature and humidity conditions in the tropics compared with other latitudes (e.g. Fischer et al. 2012; Oleson et al. 2015; Zhao et al. 2015). Some papers also conclude that heat stress extremes increase faster than temperature extremes, in both climate observations and GCM simulations (Horton et al. 2016; Li et al. 2018).

Nevertheless, most of these climatological studies express the global warming and its associated impacts on extremes as the change between a fixed historical reference and the future. Yet, the capability for ecosystems and societies to adapt to an environmental change may depend on the timescale and its associated speed of change (Klein et al. 2014; Settele et al. 2014). Chavaillaz et al. (2016) define the pace of change in mean temperature for each year as the difference between two successive 20-year periods (i.e. with a moving baseline), in order to bring new insights about the possible human perception of the global warming. The authors mainly show a strong acceleration of the running mean warming until 2080 under the strongest emission pathway (RCP8.5), with all latitudes experiencing at least a doubling in the warming rate compared with the current period. However, annual mean temperature may be far from the actual human feel-like of the climate conditions and the associated perceived climate changes.

In this study, we analyse a set of combined climate indicators that adress how future climate evolution could be perceived by population, independently of human factors. The heat stress metric illustrates the need to maintain temperature-related comfort and homoeostasis by accounting for ambient humidity, since the primary method for heat dissipation of the human body is not the exchange with a cooler environment but the sweat evaporation (Galloway and Maughan 1997; Buzan et al. 2015; Kjellstrom et al. 2016). Thus, the heat stress can be considered as a "feels-like" climate indicator compared with temperature alone (Matthews et al. 2017). We analyse the Wet-Bulb Globe Temperature (hereafter WBGT; Yaglou and Minard (1957), a well-known heat stress index. Evolutions of both temperature and WBGT are analysed, in order to assess temperature and humidity effects on the possible "perception" related to climate evolution. We particularly focus on extreme values, as we expect extremes are more indicative of a climate "feels-like" than annual and seasonal means (e.g. O'Connor et al. 1999; Leiserowitz 2006; Reser et al. 2011). To quantify how climate change could be perceived, we define the speed of change of the metrics as the difference between the 20 upcoming years and the last 20 years, as in Chavaillaz et al. (2016). 
This analysis is conducted for each year between the 1960s and 2100 using CMIP5 simulations. These speeds calculated with moving baselines are also compared with their last 20-year interannual variability, in order to assess how upcoming changes for a given year will emerge from the recent variability. This set of different indicators is used to characterise how future generations could perceive climate change due to the rapidity and the emergence of climate changes, independently of human factors. However, we do not quantify the real human perception of climate evolution, since these investigations would also require physiological and psychological factors (e.g. Leiserowitz 2006; Reser et al. 2011; Simonet 2015; Kunreuther et al. 2013; Moore et al. 2019).

\section{Approach}

\subsection{Heat extremes and CMIP5 simulations}

We focus on one heat stress index to investigate the evolution of extreme climate conditions. We analyse the simplified WBGT (Yaglou and Minard 1957; Liljegren et al. 2008; ABOM 2010), a commonly used yet approximated heat stress index (Grundstein and Cooper 2018). WBGT is calculated as:

$$
W B G T=0.567 \times T+0.393 \times V P+3.94
$$

with WBGT in unit of WBGT (or no unit), $T$ the near-surface air temperature (in ${ }^{\circ} \mathrm{C}$ ) and VP the air vapor pressure (in hPa). VP is calculated from daily data of specific humidity (q), sea-level pressure (slp) and $T$ (see detailed "Methods" in the Electronic Supplementary Materials).

$T$ and WBGT are analysed from the daily simulations of 12 GCMs of the 5th version of the Coupled Model Inter-comparison Project (CMIP5; Taylor et al. (2012)) for the historical period (1959-2005) and the RCP8.5 scenario (2006-2100). We conduct a multi-model analysis since GCMs exhibit discrepancies in their represented processes and responses (Flato et al. 2013). The 12 models are chosen according to three specific criteria: (1) all available models providing daily $T, q$ and slp for historical and future scenarios are first selected; (2) if an institute has released several model versions, the GCM with the smallest normalised distance to the observations mean as described in Knutti et al. (2013) is retained; (3) if a model provides several realisations, each realisation is weighted accordingly by the total number of realisations of the GCM, in order to equally represent each of the 12 models in the multi-model means. Features of the 12 GCMs are given in Table ESM1 of the Electronic Supplementary Materials. This subset well represents the whole set of CMIP5 models. Indeed, the equilibrium climate sensitivity as defined in Flato et al. (2013) is $3.4^{\circ} \mathrm{C}$ [2.1; 4.1] for the 12 GCMs used in this study, and $3.2^{\circ} \mathrm{C}[2.1 ; 4.4]$ for all the CMIP5 models.

CMIP5 simulations are also compared with the WATCH-Forcing-Data-ERA-Interim observations (WFDEI; Weedon et al. (2014)). This dataset presents an estimate of the daily data from 1979 to 2018, obtained from the ERA-Interim reanalysis (Dee et al. 2011) bias-corrected with direct observations (Weedon et al. 2011; Weedon et al. 2014). The corresponding historical period considered in this study is thus limited between 1979 and 2005. As a consequence, we use CMIP5 simulations from 1959 to 2100, in order to obtain the annual running speeds of change between two successive 20-year periods from 1979 to 2080. Both observations and simulations are bi-linearly interpolated onto the CCSM4 $1.25^{\circ} \times 0.9375^{\circ}$ spatial grid to plot geographical distributions. 
We analyse the yearly mean of $T$ for each year between 1959 and 2100 (hereafter $T_{\text {mean }}$ ), but mainly focus our assessment on annual hot extremes of $T$ and WBGT. For each GCM and observations, these extremes are defined as the averaged values above the annual 99th percentile of $T$ and WBGT (respectively $T_{99}$ and WBGT 99 ), since the 99th percentile definition is commonly used in extreme analyses (e.g. Fischer and Knutti 2013). Climatologies for $T_{99}$ and $\mathrm{WBGT}_{99}$ are shown in Fig. ESM1, and values are consistent with extremes obtained using annual 95th percentile in Zhao et al. (2015). WBGT is usually analysed by comparing values with danger thresholds defined in health studies (Kjellstrom et al. 2009). However, this absolute value approach comes with large uncertainties due to model biases in temperature and humidity projections (Fischer and Knutti 2013; Zhao et al. 2015), population acclimatisation (Bowler 2005) and heat stress index choices (Buzan et al. 2015). Here, we analyse the projected anomalies of the right tail of WBGT distributions instead of the frequency of occurrence of fixed values, which provides a first level of bias correction that reduces the impact of absolute value biases.

\subsection{Selected indicators}

In order to investigate the evolution of heat extremes and assess whether the evolution of global warming will be more perceived by population in $T_{99}$ or in $\mathrm{WBGT}_{99}$, a set of different statistical indicators is used. Chavaillaz et al. (2016) define the warming pace of change for each year as the difference between the averaged $T_{\text {mean }}$ over the twenty upcoming years and the averaged $T_{\text {mean }}$ over the twenty previous years. This speed with a moving baseline provides the near projected change, and as considered by the authors, brings insights on how population are going to experience a mean change within the next 20 years compared with values they just experienced. The 20 -year window is retained as an appropriate mid-point between a too long 30-year period to investigate a perceived change, and a too short 10-year period to average the year-to-year variability (Liebmann et al. 2010; Chavaillaz et al. 2016). We define the corresponding running speed of change in unit/20 years for a year $t$ as:

$$
\Delta X_{[20]}(t)=\langle X\rangle_{t, t+20}-\langle X\rangle_{t-20, t}
$$

where $X$ is the variable of interest, and $\langle X\rangle$ represents the mean over the associated 20 years. Note that $\langle X\rangle_{t 1, t 2}$ gives the temporal average between year $\mathrm{t} 1$ excluded and year $\mathrm{t} 2$ included as: $\langle X\rangle_{t 1, t 2}=\sum_{t=t 1+1}^{t 2} \frac{X}{\left(t_{2}-t_{1}\right)}$ (Chavaillaz et al. 2016). In this study, we compute the yearly running speeds for $T_{\text {mean }}$ and $T_{99}$ (in $\mathrm{K} / 20$ years) and $\mathrm{WBGT}_{99}$ (in unit of WBGT/20 years) between 1979 and 2080 (respectively $\Delta \mathrm{T}_{\text {mean [20] }}, \Delta \mathrm{T}_{99[20]}$ and $\Delta \mathrm{WBGT}_{99[20]}$ ).

Running speeds of evolution describe changes that populations are going to experience compared with what they just lived. However, since $T_{99}$ and $\mathrm{WBGT}_{99}$ cannot be directly compared due to different unit systems (Buzan et al. 2015), the speeds cannot be used to assess which of $T_{99}$ and WBGT $_{99}$ is projected to evolve the fastest. Thus, ratios between each yearly speeds of change and the corresponding mean 20-year speed over 1979-1998 are described, in order to characterise both future accelerations and also compare velocities of $T_{99}$ and $\mathrm{WBGT}_{99}$ evolutions. The historical ratio of the running speed is defined for a year $t$ as:

$$
R_{\Delta X}(t)=\frac{\Delta X_{[20]}(t)}{\left\langle\Delta X_{[20]}\right\rangle(1979: 1998)}
$$

where $X$ is the variable of interest, and $\left\langle\Delta X_{[20]}\right\rangle(1979: 1998)$ is the mean speed averaged over yearly $\Delta X_{[20]}$ between 1979 and 1998 . We select this 20 -year window as a relatively smooth reference, since ratios computed with smaller references induce important uncertainties due to interannual variabilities. Ratios calculated with a larger and/or a shifted 
historical window show smaller but similar trends (not shown here). We compute the historical ratios for $T_{\text {mean }}, T_{99}$ and $\mathrm{WBGT}_{99}$ between 1979 and 2080 (respectively $\mathrm{R}_{\Delta \text { Tmean }}$, $\mathrm{R}_{\Delta \mathrm{T} 99}$ and $\mathrm{R}_{\Delta \mathrm{WBGT}}$ ).

Hansen et al. (2012) describe the significance and the perception of climate change by comparing the mean warming with the fixed historical year-to-year variability (i.e. the standard deviation calculated over 1951-1980). World Bank (2013) re-uses this approach and define an unusual hot season anomaly as a change at least 3 times larger than the fixed historical year-to-year variability, and an unprecedented anomaly as a change at least 5 times larger. However, we argue that future populations will not compare annual running evolutions they recently experienced to the fixed interannual variability over 1951-1981. Therefore, we normalise each $\Delta \mathrm{X}_{[20]}$ computed for a year $t$ with each corresponding previous 20-year year-to-year variability as:

$$
\alpha_{X}(t)=\frac{\Delta X(t)}{\operatorname{std}(X(t-20, t))}
$$

where $X$ is the variable of interest, and $\operatorname{std}()$ is the standard deviation, here calculated over the 20 annual values of the considered period. We compute these ratios for $T_{\text {mean }}, T_{99}$ and WBGT $99_{9}$ between 1979 and 2080 (respectively $\alpha_{\text {Tmean }}, \alpha_{\text {T99 }}$ and $\alpha_{\text {WBGT99). }}$ ).

We then quantify the yearly fraction of the world population that will be exposed to a rapid and possible severely perceived change. Statistically, a $\alpha$ of 2 indicates a shift of a Gaussian distribution that gives $50 \%$ of the new distribution higher than the corresponding $98 \%$ of the initial distribution (i.e. the former 98th percentile becomes the new 50th percentile). As a consequence, Chavaillaz et al. (2016) define an extremely warm year when the speed of change between two consecutive 20-year periods is above the 98th percentile of the running baseline distribution (i.e. $\alpha \geq 2$ ). Following this approach, we consider a significant and rapid change for each year when $\Delta X_{[20]}$ is at least twice exceeding the std over the running baseline. We define the corresponding severely exposed population as the sum of the population from every countries where $\alpha \geq 2$ (in $\%$ of total population) as:

$$
\Phi_{X[\alpha \geq 2]}(t)=\sum_{c=\text { countries }} \delta_{X}(t) \times P_{c}(t)
$$

where $X$ is the variable of interest, $\delta_{X}(t)$ in [0:1] is the fraction of $c$ where $\alpha \geq 2$, and $\mathrm{P}_{c}(t)$ indicates the total estimated population of the country $c$ for the year $t$. Current and future population estimations are obtained from the United Nations (UN) for the 1960 2050 period (databank.worldbank.org), and reach a total of 9.5 billion people by 2050 . After 2050, we approximate that population evolves with the 2041-2050 mean rate of each country, and reaches about 10.5 billion people by 2080 . This evolution corresponds to the mean evolution of the RCP projections ( 8.5 to 12 billion in 2100 according to van Vuuren et al. (2011)). Recent exposure studies analyse the shared socio-economic pathways (SSP) that provide total population scenarios used to derive climate change projections (Jones and O’Neill 2016; Riahi et al. 2017). Though SSP give projections until 2100, they only provide estimations at 10-year intervals between 2010 and 2100. Therefore, we choose to calculate the severely exposed population from the UN projections, since we consider that the yearly resolution provided is more accurate to investigate the perceived evolution of heat extremes. The severely exposed population is computed for $T_{\text {mean }}, T_{99}$ and WBGT $_{99}$ between 1979 and 2080 (respectively $\phi_{\text {Tmean }}, \phi_{\text {T99 }}$ and $\phi_{\text {WBGT99 }}$ ). 


\section{Results}

\subsection{Geographical distributions of the speeds}

Global patterns of the speeds of change are analysed, and the corresponding values are described with the multi-model ensemble mean and the 5-95\% ranges from the 12 GCM distribution. The largest $\Delta \mathrm{T}_{\text {mean[20] }}$ is located over northern high latitudes during all of twenty-first century (Fig. 1a, b and c). The global mean change over land accelerates until 2080 and reaches $\Delta \mathrm{T}_{\text {mean[20] }}$ of $+1.8[1.3 ; 2.2] \mathrm{K} / 20$ years in northern high latitudes and $+1.1[0.6 ; 2] \mathrm{K} / 20$ years in the tropics (Fig. 1c). These patterns are consistent with the projected warming between historical and future, and confirm the Arctic hotspot (Collins et al. 2013). Geographical distributions are also consistent with previous results that show a mean global $\Delta \mathrm{T}_{\text {mean[20] }}$ larger than $+1.5 \mathrm{~K} / 20$ years in northern high latitudes in 2080 under the RCP8.5 scenario (Chavaillaz et al. 2016).

By the end of the twenty-first century, the maximum $\Delta \mathrm{T}_{99[20]}$ is located over "midcontinental areas" (i.e. Europe, northern America and Amazonia) at the opposite of

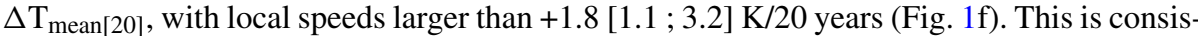
tent with patterns of the maximum $T_{99}$ increase between 1986-2005 and 2081-2100 (e.g.
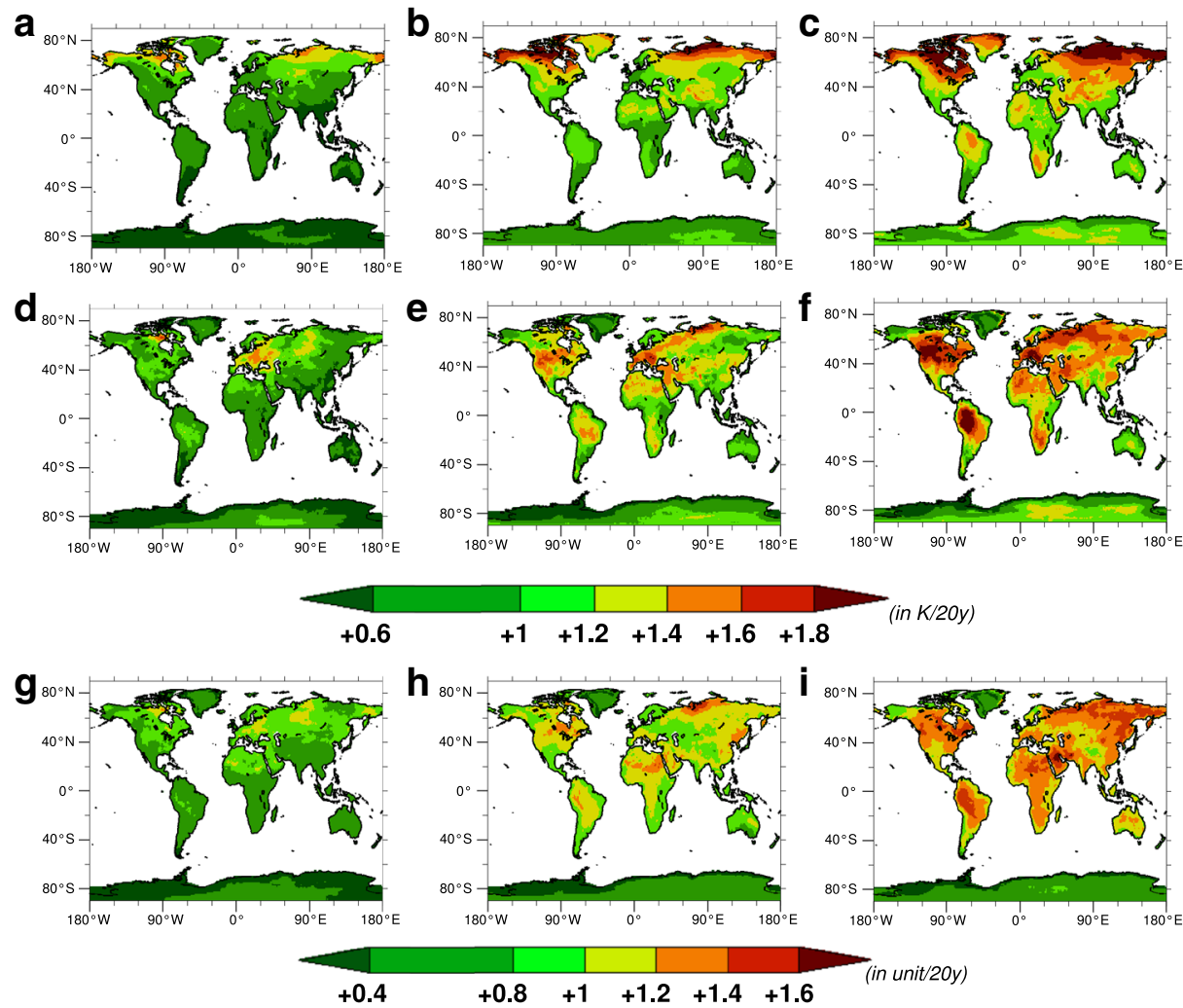

Fig. 1 Multi-model ensemble means of running speeds of change between two successive 20-year periods calculated from 12 CMIP5 models under the RCP8.5 scenario for year 2000, 2040 and 2080 for: (a-b-c) $\mathrm{T}_{\text {mean }}$ in K/20y, (d-e-f) $\mathrm{T}_{99}$ in K/20y, and (g-h-i) $\mathrm{WBGT}_{99}$ in unit of WBGT/20y 
Fischer and Knutti 2013; Coffel et al. 2018). However, the largest $\Delta \mathrm{T}_{99[20]}$ during early 2000s is located only over eastern Europe (Fig. 1d). The moderated $\Delta \mathrm{T}_{99[20]}$ in Amazonia and northern America during these years suggests a larger acceleration of the $T_{99}$ warming between 2000 and 2080 in northern America and Amazonia compared with Europe.

The global $\Delta \mathrm{WBGT}_{99[20]}$ is spatially more homogeneous than $\Delta \mathrm{T}_{\text {mean[20] }}$ and $\Delta \mathrm{T}_{99[20]}$ during the twenty-first century under the RCP8.5 scenario (Fig. 1g, h and i). These more homogeneous patterns are consistent with previous analyses of the total projected change (e.g. Zhao et al. 2015; Brouillet and Joussaume 2019). By 2080, the largest $\Delta$ WBGT $_{99[20]}$ of $+1.4[1.1 ; 2.2]$ unit/20 years is located in Amazonia, the region between Sahel and Arabia (hereafter the "SAA region") and in north-eastern Asia (Fig. 1i). However, the large $\triangle$ WBGT $_{99[20]}$ within north-eastern Asia in 2080 is not a particular hotspot when analysing the total projected changes in $\mathrm{WBGT}_{99}$ between historical and future periods (Zhao et al. 2015). Moreover, unlike the well-known larger future increase in $\mathrm{WBGT}_{99}$ in the tropics than in mid-latitudes, the $\Delta \mathrm{WBGT}_{99[20]}$ in 2000 is smaller within the tropics than in midlatitudes (Fig. 1g).

Geographical distributions of the speeds of change show faster increases in $T_{\text {mean }}, T_{99}$ and $\mathrm{WBGT}_{99}$ during the second half of the twenty-first century. Different regions of interest are highlighted to experience either faster $\Delta \mathrm{T}_{99[20]}$ such as Europe and Amazonia, and/or faster $\Delta \mathrm{WBGT}_{99[20]}$ such as Amazonia, the SAA region and north-eastern Asia. Therefore, regional averaged speeds of change are analysed to compare these regions among themselves. This regional approach also enables to assess the CMIP5 inter-model spread in the quantification of the speeds of evolution.

\subsection{Regional means}

The largest regional $\Delta \mathrm{T}_{\text {mean[20] }}$ over land is confirmed to occur within northern high latitudes during all of twenty-first century under the RCP8.5 scenario and increase until 2080 (Fig. 2b). Regional $\Delta \mathrm{T}_{\text {mean [20] }}$ also exhibits large differences amongst regions that increases from $1979\left(\Delta \mathrm{T}_{\text {mean[20] }}\right.$ in $[+0.25 ;+0.5 \mathrm{~K} / 20$ years $\left.]\right)$ to $2080\left(\Delta \mathrm{T}_{\text {mean[20] }}\right.$ in $[+0.8$ to +1.5 $\mathrm{K} / 20$ years]).

Time series of $\Delta \mathrm{T}_{99[20]}$ show the global increase of running speed of change of $T_{99}$ during the twenty-first century (Fig. 2e). The fastest $T_{99} 20$-year upcoming warming over all the period is simulated in Europe until 2075. From 2075, Amazonia shows the largest $\Delta \mathrm{T}_{99[20]}$. Europe is also simulated to experience a substantial $\Delta \mathrm{T}_{99[20]}$ increase from 1979 to peak around 2005 (Fig. 2e). This "bump" may result from the large observed and simulated regional decrease in sulphate aerosols (Cusack et al. 2012; Szopa et al. 2013), that weakens the associated negative radiative forcing between 1980-2000 and 2000-2020 in summer (Szopa et al. 2013). This aerosol forcing may also explain the similar but smaller and delayed trends of $\Delta \mathrm{T}_{99[20]}$ in other regions between 1990 and 2015 (Fig. 2e). Regional $\Delta \mathrm{T}_{99[20]}$ is larger than $\Delta \mathrm{T}_{\text {mean[20] }}$ for all latitudes, except in northern high latitudes. $\Delta \mathrm{T}_{99[20]}$ shows a more pronounced interannual variability per region, and smaller regional differences (Fig. $2 \mathrm{~b}$ and e). These smaller differences are explained by the stronger spatial variability in $\Delta \mathrm{T}$ during the coldest seasons than during the hottest seasons of the year (not shown here).

Along with temperatures, regional $\triangle \mathrm{WBGT}_{99[20]}$ is projected to increase until 2080, showing an accelerated WBGT$_{99}$ intensification (Fig. 2h). Regions with high historical $\mathrm{WBGT}_{99}$ values such as the SAA region and Amazonia (Fig. ESM1) are projected to experience an upcoming $\Delta \mathrm{WBGT}_{99[20]}$ in 2080 larger than +1.2 unit/20 years. This speed corresponds to an increase of one danger threshold defined in health studies every 

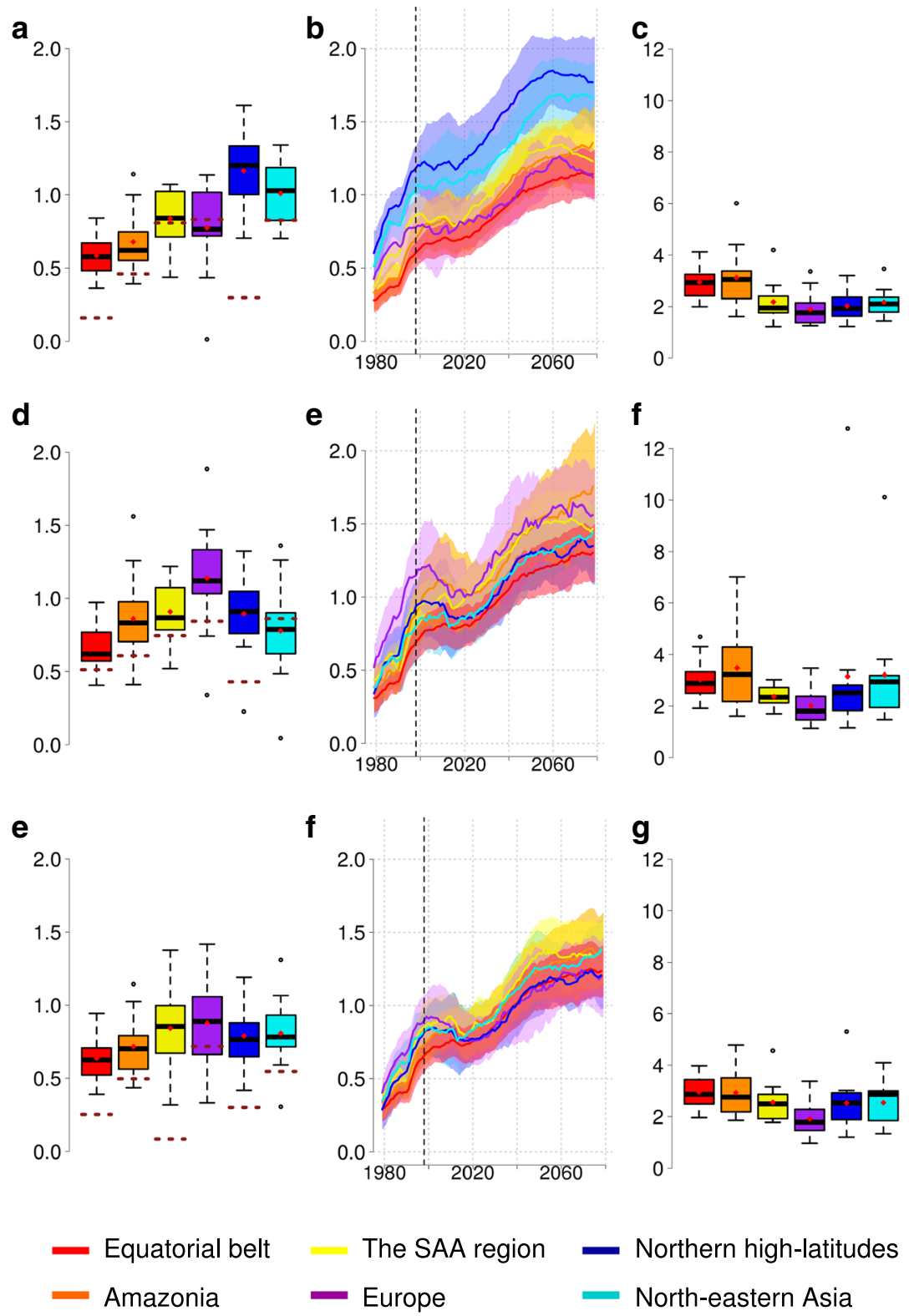

Fig. 2 (a-d-g) Boxplots of the 12 models regional running speeds of change over land for the year 1998 (i.e. speed calculated as the difference between 1979-1998 and 1999-2018 periods), respectively for $T_{\text {mean }}$ (in $\mathrm{K} / 20 \mathrm{y}$ ), $T_{99}$ (in K/20y) and $\mathrm{WBGT}_{99}$ (in unit/20y). Solid black thick lines represent the multi-model medians and red diamonds show the multi-model means. Dashed dark red lines indicate the corresponding WFDEI observations running speed per region for 1998. Regions correspond to the boxes displayed in Fig. ESM2. (b-e-h) Corresponding time series of multi-model mean running speeds of change between 1979 and 2080 under the RCP8.5 scenario, respectively for $T_{\text {mean }}, T_{99}$ and $\mathrm{WBGT}_{99}$. Solid colour lines show the multi-model means. Shaded envelops indicate the $95 \%$ confidence interval of the inter-model spread. (c-f-i) Boxplots of the 12 GCMs regional normalised speeds with the historical mean speed over 1979-1998 for the year 2080, respectively for $T_{\text {mean }}, T_{99}$ and $\mathrm{WBGT}_{99}$ 
20 years (Kjellstrom et al. 2009; ABOM 2010). Differences between regions are smaller in $\Delta$ WBGT $_{99[20]}$ than in $\Delta \mathrm{T}_{\text {mean[20] }}$ and $\Delta \mathrm{T}_{99[20]}$. This is consistent with a stronger warming in mid-latitudes but a greater increase of VP in the tropics that results in a spatially more homogeneous WBGT change (Zhao et al. 2015). These smaller differences may also be amplified by the associated projected decrease in relative humidity over areas with the greatest projected warming that attenuates the corresponding future $\mathrm{WBGT}_{99}$ increase (Byrne and O'Gorman 2013, 2016; Brouillet and Joussaume 2019).

Simulated regional speeds are also compared with WFDEI observations for the year 1998 (Fig. 2a, d and g). In 1998, CMIP5 models overestimate $\Delta \mathrm{T}_{\text {mean[20] }}$ in the equatorial belt, Amazonia and northern high latitudes, and well represent $\Delta \mathrm{T}_{\text {mean[20] }}$ in the SAA region and Europe (Fig. 2a). $\Delta \mathrm{T}_{99[20]}$ and $\Delta \mathrm{WBGT}_{99[20]}$ show a global overestimation in the GCMs compared with WFDEI (Fig. $2 \mathrm{~d}$ and g). For each metric, regional means tend to be better simulated than latitudinal means, except for $\Delta \mathrm{WBGT}_{99[20]}$ in the SAA region. The multimodel global overestimation of historical speeds is however consistent with the observed so-called hiatus in the annual mean warming that is not well represented in CMIP5 models (Flato et al. 2013).

In this work, we particularly focus on the RCP8.5 scenario, since it provides a clearer signal to the global warming and it is usually considered as the near-continuation of the current emissions pathway. Yet, the analysis of a mitigation future scenario brings an additional measure of the RCP uncertainties. Time series of $\Delta \mathrm{T}_{\text {mean[20] }}, \Delta \mathrm{T}_{99}$ [20] and $\Delta \mathrm{WBGT}_{99[20]}$ are thus also analysed under the RCP2.6 scenario for 7 CMIP5 models (see Table ESM2) and displayed in Fig. ESM3. This smaller subset of CMIP5 models is explained by the reduced number of models providing daily data for RCP2.6. As expected, speeds of change increase for all metrics until 2005 and then decrease until 2080 (Fig. ESM3, Chavaillaz et al. (2016)). However, relative behaviours between regions highlighted for both 12 and 7 GCMs for RCP8.5 (Fig. 2 and Fig. ESM4) are confirmed under the RCP2.6 mitigation scenario.

In many studies, $T$ and heat stress are directly compared (e.g. Zhao et al. 2015; Matthews et al. 2017; Li et al. 2018). When directly comparing $T$ and WBGT, regional values of $\Delta \mathrm{T}_{99[20]}$ are larger than $\Delta \mathrm{WBGT}_{99[20]}$ for all latitudes between 1979 and 2080 (Fig. 2e and $h$ ). Future increase of $\Delta \mathrm{T}_{99[20]}$ also tends to be stronger than the intensification of

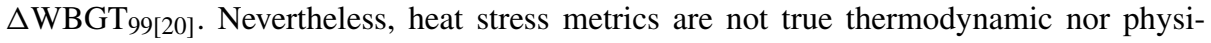
cal quantities, and they are described with temperature scales for comparative purposes only (Buzan et al. 2015). Therefore, relative accelerations and speeds of change of $T_{99}$ and $\mathrm{WBGT}_{99}$ cannot be analysed by comparing values of $\Delta \mathrm{T}_{99[20]}$ and $\Delta \mathrm{WBGT}_{99[20]}$, and alternative analyses are necessary.

\subsection{Acceleration of the projected evolutions}

Since $\Delta \mathrm{T}_{99[20]}$ and $\Delta \mathrm{WBGT}_{99[20]}$ cannot be directly compared, we quantify the historical ratios of the speeds of $T_{\text {mean }}, T_{99}$ and $\mathrm{WBGT}_{99}$, to assess their accelerations and characterise which of them is projected to evolve the fastest. In $2080, \mathrm{R}_{\Delta \text { Tmean }}$ reaches a multi-model mean of almost 2 in northern latitudes and the SAA region, and 2.8 to 3 within the tropics under the RCP8.5 scenario (Fig. 2c). Thus, despite a stronger $\Delta \mathrm{T}_{\text {mean[20] }}$ in northern latitudes than in the tropics (Fig. 2a and b), $R_{\Delta \text { Tmean }}$ shows that the projected $T_{\text {mean }}$ warming will be faster in tropical areas than in mid-latitudes compared to historical and current changes (consistent with Chavaillaz et al. (2016)). $\mathrm{R}_{\Delta \mathrm{T} 99}$ is projected to reach values of 1.9 to 2.5 in northern latitudes, and values above 2.9 in the equatorial belt in 2080 (Fig. 2f). Despite the largest $\Delta \mathrm{T}_{99[20]}$ projected in Europe, the associated $\mathrm{R}_{\Delta \mathrm{T} 99}$ in 2080 is the smallest. For all latitudes, $\mathrm{R}_{\Delta \mathrm{T} 99}$ shows similar values than $\mathrm{R}_{\Delta \mathrm{Tmean}}$. Models exhibit larger 
inter-model spreads in $\mathrm{R}_{\Delta \mathrm{T} 99}$ than in $\mathrm{R}_{\Delta \mathrm{Tmean}}$, particularly over Amazonia and northern high latitudes (Fig. 2f). In Amazonia, this can be explained by the well-known CMIP5 model uncertainties in the future projected drying over Amazonia that may amplify or hamper the temperature extreme changes (Good et al. 2008; Marengo and Espinoza 2016). For northern high latitudes, the MIROC5 model simulates very small historical averaged $\Delta \mathrm{T}_{99[20]}$ over land (not shown here) that induces a regional projected acceleration larger than nine times the 1979-1998 mean $\Delta \mathrm{T}_{99[20]}$ (Fig. 2f). Similarly to $\mathrm{R}_{\Delta \mathrm{Tmean}}$, and $\mathrm{R}_{\Delta \mathrm{T} 99}$, the largest $\mathrm{R}_{\triangle \text { WBGT99 }}$ is projected within the equatorial belt by up to 2.8 , and the smallest $\mathrm{R}_{\triangle \text { WBGT99 }}$ is projected over Europe (Fig. $2 \mathrm{i}$ ). The inter-model spread in $\mathrm{R}_{\Delta \text { WBGT99 }}$ for each region is larger than $\mathrm{R}_{\Delta \text { Tmean }}$ but is smaller than $\mathrm{R}_{\Delta \mathrm{T} 99}$.

According to CMIP5 simulations, increases in $R_{\Delta}$ highlight that $T_{\text {mean }}, T_{99}$ and $\mathrm{WBGT}_{99}$ future intensifications with a moving baseline will be faster in the tropics than in the midlatitudes, despite the faster projected warming in mid- and high latitudes. In particular, the well-known hotspot of the projected change in $T_{99}$ within Europe (e.g. Fischer and Knutti 2013) exhibits the smallest acceleration between historical and the end of the twenty-first century. This small acceleration can be explained by the stabilisation of $\Delta \mathrm{T}_{99[20]}$ around 2060 in Europe (Fig. 2e) and is independent from the corresponding large warming over the past few decades (not shown here). This stabilisation of the speed could be related to the well-known regional feedbacks of $T_{99}$ with land-atmosphere fluxes (Seneviratne et al. 2006; Diffenbaugh et al. 2007; Hirschi et al. 2011; Donat et al. 2017; Vogel et al. 2017; Seneviratne et al. 2018).

$\mathrm{R}_{\Delta \mathrm{Tmean}}, \mathrm{R}_{\Delta \mathrm{T} 99}$ and $\mathrm{R}_{\Delta \text { WBGT99 }}$ show very similar accelerations between 1979 and 2080 at both regional and latitudinal scales. $\mathrm{WBGT}_{99}$ does not clearly increase faster than $T_{99}$, and a slight faster increase of $T_{99}$ compared with $\mathrm{WBGT}_{99}$ is exhibited within the Amazon basin (Fig. $2 \mathrm{f}$ and i). Since higher temperatures drive greater increments in heat stress indexes at a given relative humidity, these similar accelerations stand in contrast with the expected Clausius-Clapeyron effect (Davies-Jones 2008; Fischer et al. 2012). However, the projected global strong decrease in relative humidity during heat extremes in CMIP5 models might explain the similar accelerations, particularly between $T_{99}$ and WBGT$_{99}$ (Brouillet and Joussaume 2019).

\subsection{Rapidity and emergence of $T_{99}$ and $\mathrm{WBGT}_{99}$ changes}

In order to better investigate how the evolution of the considered metrics could be perceived, we compare each yearly speed of change to their recent experienced year-to-year variability. According to CMIP5 simulations, the corresponding $\alpha_{\text {Tmean }}$ is globally projected to increase between 1979 and 2040 under the RCP8.5 scenario, and then stabilise to reach at least 1.5 in 2080 (Fig. 3a). Models project an increase in $\alpha_{\mathrm{T} 99}$ as well for all latitudes until 2080 (Fig. 3b). Tropical areas show a $\alpha_{\mathrm{T} 99}$ of 1 before 1995, and reach a $\alpha_{\mathrm{T} 99}$ of 1.7 to 1.9 by 2080 , whereas northern latitudes barely reach a $\alpha_{\mathrm{T} 99}$ of 1 . In the tropics, this shows that future population in 2080 will experience a $T_{99}$ warming within the next 20 years almost twice larger than the variability they just experienced over the last 20 years under the RCP8.5 scenario. The lower interannual tropical variability in both mean and extreme temperatures mainly explains the greater tropical $\alpha_{\text {Tmean }}$ and $\alpha_{\mathrm{T} 99}$ than in midlatitudes. The smaller year-to-year variability in $T_{\text {mean }}$ than in $T_{99}$ also explains the larger $\alpha_{\text {Tmean }}$ compared with $\alpha_{\mathrm{T} 99}$ for each considered region. $\alpha_{\mathrm{T} 99}$ is characterised by small differences between tropical regions, at the opposite of an important $\Delta \mathrm{T}_{99[20]}$ and $\mathrm{R}_{\Delta T 99}$ regional spread between equatorial belt, Amazonia and SAA region (Fig. 3b, and e). As for temperatures, $\alpha_{\text {WBGT99 }}$ is projected to increase until 2080 (Fig. 3c). Indeed, $\alpha_{\text {WBGT99 }}$ exhibits 

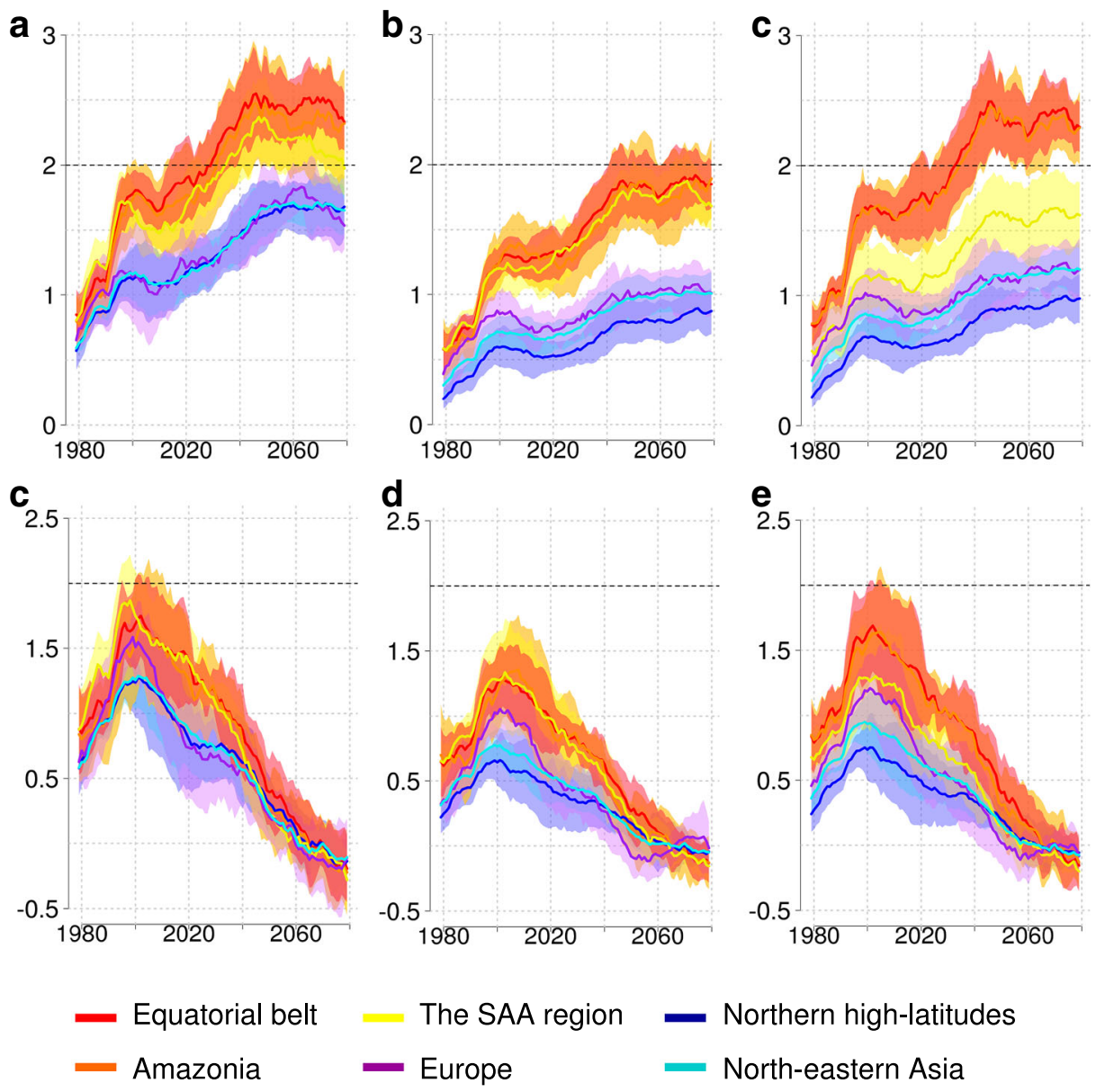

Fig. 3 Multi-model ensemble mean regional normalised running speeds with the year-to-year variability over the last 20 years for each year between 1979 and 2080 under the RCP8.5 scenario for Tmean $\left(\alpha_{\text {Tmean }}\right.$ in a), T99 $_{9}\left(\alpha_{\text {T99 }}\right.$ in b) and WBGT $99\left(\alpha_{\text {WBGT99 }}\right.$ in c). $\alpha_{\text {Tmean }}, \alpha_{\text {T99 }}$ and $\alpha_{\text {WBGT99 }}$ are also calculated under the RCP2.6 scenario, and are respectively displayed in (d), (e) and (f). Solid lines represent the multi-model means. Shaded envelops indicate the $95 \%$ confidence interval of the inter-model spread

a larger future $\Delta \mathrm{WBGT}_{99[20]}$ compared with the corresponding just experienced interannual variability than the current $\Delta$ WBGT $_{99[20]}$ compared with the last 20-year variability. As for $\alpha_{\text {T99 }}, \alpha_{\text {WBGT99 }}$ also increases more in tropical areas than in mid-latitudes. Within the tropics, we show that the future upcoming intensification in $\mathrm{WBGT}_{99}$ will be more than twice larger than the future just-experienced $\mathrm{WBGT}_{99}$ year-to-year variability. Significant regional differences in $\alpha_{\text {WBGT99 }}$ are exhibited and increase until 2080. Except for the SAA region, $\alpha_{\text {WBGT99 }}$ is larger than $\alpha_{\text {T99 }}$ over land during all the period, with $\alpha_{\text {WBGT99 }}$ values between 1.2 in Europe to 2.3 in the equatorial belt and Amazonia in 2080 (Fig. 3c). This larger $\alpha_{\text {WBGT99 }}$ than $\alpha_{\text {T99 }}$ might be due to a smaller year-to-year variability in WBGT than in $T$ (Zhao et al. 2015).

CMIP5 simulations show that future $\Delta \mathrm{T}_{99[20]}$ and $\Delta$ WBGT $_{99[20]}$ will be larger than their last 20-year variabilities, at the opposite of the current speeds. In particular, projections show that populations in the tropics will experience fast $T_{99}$ and $\mathrm{WBGT}_{99}$ intensifications under 
the RCP8.5 scenario compared with the historical change they are used to. These future intensifications will be 1.5 larger than the future just-experienced variabilities, while these speeds of change are historically smaller than historical interannual variabilities $(\alpha \leq 1)$. Comparison with future recent variability also exhibits that the increase in extremes will be more significant and faster in $\mathrm{WBGT}_{99}$ than in $T_{99}$ for populations. We thus argue that the evolution of extremes will be more perceived when considering the humidity effect and its variations on people $\left(\mathrm{WBGT}_{99}\right)$ than the temperature increase only $\left(T_{99}\right)$. Previous works have shown that an associated drying is projected in CMIP5 models over mid-continental areas that hamper the heat stress intensification (e.g. Coffel et al. 2019; Brouillet and Joussaume 2019). We confirm that, despite this drying dampening effect, the global warming consequences on populations will remain faster and more significant in heat stress than in temperature extremes, particularly in the tropics.

Same analyses are conducted under the RCP2.6 scenario for the corresponding subset of 7 GCMs. As expected, both $\alpha_{\text {T99 }}$ and $\alpha_{\text {WBGT99 }}$ increase until 2000-2005 to reach their regional maxima, and then decrease until 2080 for RCP2.6 (Fig. 3e and f). Nevertheless, $\alpha_{\text {WBGT99 }}$ remains higher than $\alpha_{\text {T99 }}$ from 1979 to 2080 for all regions. $\alpha_{\text {WBGT99 }}$ is also larger than 1 from 1987 to 2030 in the tropics, whereas $\alpha_{\mathrm{T} 99}$ is larger than 1 only from 1993 to 2020. This confirms the higher speeds of change compared with their recent interannual variabilities in $\mathrm{WBGT}_{99}$ than in $T_{99}$, exhibited with RCP8.5 independently of the number of GCMs (Fig. ESM5). This also emphasises that the response of the global warming is simulated at least until 2020-2030 even under the smallest emission pathway, and particularly in WBGT extremes.

\subsection{Population exposure}

We quantify the projected exposure to a significant change of $T_{99}, \mathrm{WBGT}_{99}$ and $T_{\text {mean }}$ for a given year (respectively $\phi_{\mathrm{T} 99}, \phi_{\mathrm{WBGT} 99}$ and $\phi_{\mathrm{Tmean}}$ ), and express it as the yearly percentage of the total world population to take into account the projected increasing demography. Figure 4 displays the evolution of the exposure to fast running changes (i.e. $\alpha \geq 2$ ) between 1986 and 2080 according to CMIP5 models and UN projections. $\phi_{\text {T99 }}$ increases during the twenty-first century, and reaches a maximum value of $16 \%$ of the total world population in 2066 (about 1.7 billions of people). $\phi_{\text {WBGT99 }}$ is projected to increase more and faster, already reaches $16 \%$ of the population in 2030, and $36 \%$ by 2067 (3.5 billion of people). The exposure is thus projected to be greater in $\mathrm{WBGT}_{99}$ than in $T_{99}$, implying that more people will be exposed to a more severe recent $\mathrm{WBGT}_{99}$ increase than for $T_{99}$. GCMs project a greater $\phi_{\text {Tmean }}$ than both $\phi_{\text {T99 }}$ and $\phi_{\text {WBGT99, }}$, with more than $40 \%$ of the population exposed to a fast and significant evolution of $\mathrm{T}_{\text {mean }}$ from 2040, and a maximum of $43 \%$ in 2060 ( 4.2 billion of people). This larger exposure is explained by the corresponding smaller interannual variability in mean values than in extremes that results in larger emergent changes in $T_{\text {mean }}$ than in $T_{99}$ or $\mathrm{WBGT}_{99}$. However, $T_{\text {mean }}$ is more difficult to link to the possible human perception of climate changes compared with $T_{99}$ and WBGT 99 . Corresponding exposures for RCP2.6 show a global population exposed to $\alpha \geq 2$ significantly smaller under this scenario for all the metrics analysed (Fig. ESM6).

\section{Implications on the perception and discussions}

This paper addresses how the evolution of the heat extremes could be perceived during the twenty-first century only using climate indicators, and mainly under the RCP8.5 


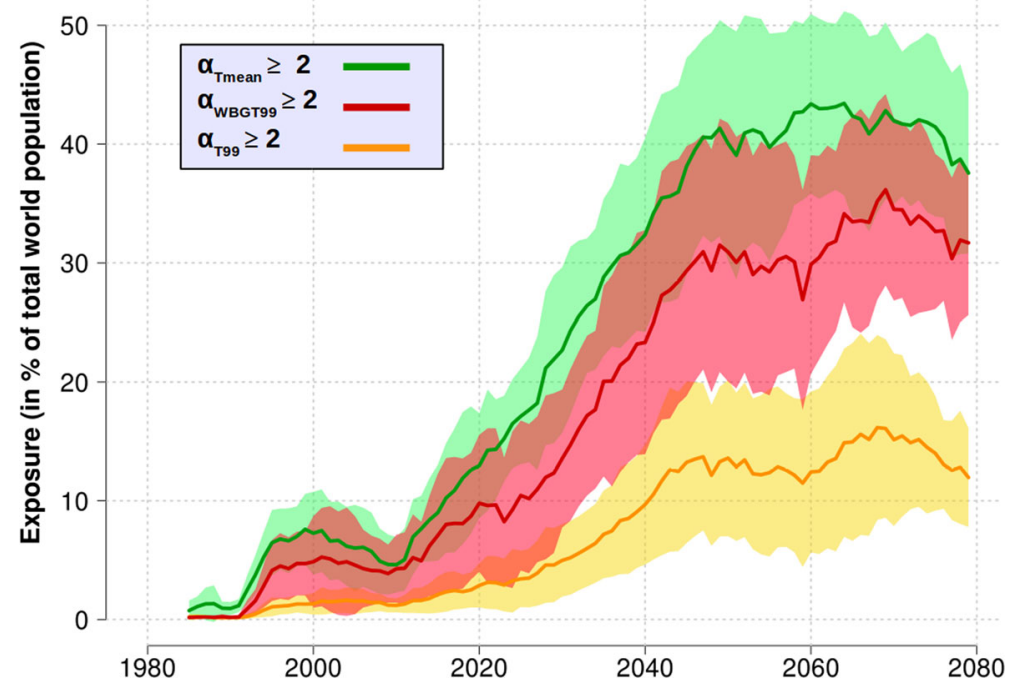

Fig. 4 Multi-model ensemble mean global exposure to a significant running speed $(\alpha \geq 2)$ between 1986 and 2080 under the RCP8.5 scenario (in \% of total annual world population) for $T_{\text {mean }}$ (green), $T_{99}$ (orange) and WBGT $_{99}$ (red). The population of each country follows the average UN projections until 2050, and evolves with the 2041-2050 rate until 2080. Solid lines represent the multi-model means. Shaded envelops indicate the $95 \%$ confidence interval of the inter-model spread

scenario. We also assess whether this perceived evolution will be stronger when considering the humidity effect on the human body (heat stress) or when considering the temperature effect alone. According to CMIP5 simulations, and using the simplified Wet-Bulb Globe Temperature as our heat stress index, a strong future acceleration of both extremes of temperature $\left(T_{99}\right)$ and heat stress (WBGT 99 ) changes is shown for RCP8.5. $T_{99}$ and $\mathrm{WBGT}_{99}$ are projected to globally increase with similar accelerations until 2080, exhibiting that both extremes will intensify as fast as each other. Regional means oppositely show a faster future $T_{99}$ warming in the future in Amazonia, and a faster WBGT $_{99}$ intensification within the Sahel to Arabia region ("the SAA region"). This difference can be explained by the relative humidity $(\mathrm{RH})$ variations effect. $\mathrm{RH}$ is projected to strongly decrease in Amazonia but to slightly increase over the SAA region between 1979 and 2100 (Brouillet and Joussaume 2019). Although the drying (wettening) enhances (dampens) the $T_{99}$ warming due to less soil moisture that enhances sensible heat flux (Fischer and Knutti 2013), it dampens (enhances) the $\mathrm{WBGT}_{99}$ intensification. In previous studies, the Apparent Temperature (Steadman 1984), another commonly used heat stress index, is projected to globally evolve faster than temperature extremes under different scenarios in CMIP5 (Li et al. 2018). A more pronounced increase in the Humidex index (Masterton and Richardson 1979) than air temperature extremes over Europe is also projected when analysing EURO-CORDEX simulations (Scoccimarro et al. 2017). The assessment of the heat stress rate of change thus may depend on the heat stress index choices. Zhao et al. (2015) conducted a comparison of the projected changes between these three heat stress indexes and temperature extremes. Though they did not analyse time series, they show for each index that the heat stress is globally projected to increase more than temperature, except in arid regions (Zhao et al. 2015). These previous works approximate that heat stress indexes can be considered 
as measurements of a temperature, and they directly compare heat stress and temperature extremes. Nevertheless, as emphasised by Buzan et al. (2015) "most of the [heat stress] metrics have units of temperature which may be misleading. The metrics have temperature scales for comparative purposes only, as the metrics are an index, not a true thermodynamic quantity". In our study, we consider that both metrics should not be directly compared, unless using adimensional metrics. As a consequence, we show similar speed of change of both temperature and heat stress extremes, and do not corroborate conclusions of previous studies.

According to CMIP5 simulations, both running speeds of change of $T_{99}$ and $\mathrm{WBGT}_{99}$ are projected to be multiplied by 2 in northern mid-latitudes and by 3 to 4 in the tropics between 1980 and 2080 under the RCP8.5 scenario. However, despite similar future acceleration in both metrics changes, a larger future speed of change compared with the just-experienced year-to-year variability is exhibited in $\mathrm{WBGT}_{99}$ than in $T_{99}$ in 2080, particularly in the tropics. This implies that the $\mathrm{WBGT}_{99}$ future intensification will be more emergent from the just-experienced variability, and will be possibly more perceived by population than the $T_{99}$ future warming. This is also emphasised under the RCP2.6 scenario until 20202030. Regions with already high values of $\mathrm{WBGT}_{99}$ such as Amazonia and the SAA region (Fig. ESM1) are also projected to experience a $\mathrm{WBGT}_{99}$ running speed of change larger than +1.2 unit/20 years in RCP8.5, which corresponds to an increase of at least one danger threshold defined in health studies (Kjellstrom et al. 2009; ABOM 2010; Buzan et al. 2015) every 20 years. This may lead to a strong perceived $\mathrm{WBGT}_{99}$ upcoming increase by population in these areas due to combined high values and fast changes. More importantly, since four danger thresholds have been defined in health analysis, this fast intensification will lead to a rapid saturation of the most dangerous classes of heat stress that will essentially increase morbidity and mortality (e.g. Mora et al. 2017). The importance of considering humidity parameters and associated variations when conducting climate change impact studies is thus confirmed in this work (e.g. Scoccimarro et al. 2017; Mora et al. 2018; Senevirantne et al. 2018).

The running speed of change methodology used here may depend on the number of realisations for each GCM, the multi-model spread, the year-to-year variability and the number of years in the selected window of reference. Some regions such as Amazonia exhibit a strong inter-model spread, particularly when analysing $\mathrm{R}_{\Delta \mathrm{T} 99}$ (Fig. 2f). This inter-model spread can be explained by the different GCM sub-seasonal responses to a mean global warming. Indeed, seasonal cycles in Amazonia are differently represented in each GCM for both historical and future period (Supplementary Information in Brouillet and Joussaume (2019)), which may induce different responses in $T_{99}$ and WBGT $_{99}$. Nevertheless, the lack of high-resolution humidity observations and a moderately good representation of the hydrological cycle in CMIP5 models limit the confidence in projected (and observed) humidity changes (Mora et al. 2017; Chen et al. 2018; Freychet et al. 2020). Though these uncertainties among the models may increase the uncertainties in the regional results we provide, the multi-model approach enables significant results in mean CMIP5 projections.

We show that a large part of the total world population will be exposed to significant $T_{99}$ and $\mathrm{WBGT}_{99}$ increases by 2080 under the RCP8.5 scenario. More than 1.7 billion of people will be exposed to a severe $T_{99}$ increase by 2060 under the RCP8.5 scenario, and more than 4.3 billion of people will be exposed to a severe WBGT $_{99}$ intensification, respectively corresponding to $17 \%$ and $44 \%$ of the total world population. At the opposite, less than $8 \%$ of the population will be exposed to a severe $\mathrm{WBGT}_{99}$ change under the RCP2.6 scenario (less than $4 \%$ for $T_{99}$ ). Regional exposures emphasise that more than 60 to $80 \%$ of the western-central Africa and Amazonia populations are projected to experience changes in 
$T_{99}$ and $\mathrm{WBGT}_{99}$ at least twice larger than the recent variability during the second half of the twenty-first century for RCP8.5 (Fig. ESM7). Moreover, the most vulnerable regions to dangerous heat and humidity combinations are also the most densely populated (Coffel et al. 2018). Although this can drive the larger exposure in $\mathrm{WBGT}_{99}$ than in $T_{99}$, large exposures in Amazonia and western-central Africa shown here may imply that population in these regions will be the most severely impacted by fast and emergent upcoming WBGT $_{99}$ intensification in the future.

Acknowledgements We acknowledge the World Climate Research Programme's Working Group on Coupled Modelling, which is in charge of the fifth Coupled Model Intercomparison Project, and we thank the climate modelling groups for producing and making available their model output. To conduct the analyses, this study benefited from the IPSL Prodiguer-Ciclad facility which is supported by CNRS, UPMC, Labex L-IPSL which is funded by the ANR (Grant ANR-10-LABX-0018) and by the European FP7 IS-ENES2 project (Grant 312979). We thank the two anonymous reviewers for their relevant comments that strongly improve the paper.

Data availability CMIP5 data used in this paper are freely available at https://esgf-node.llnl.gov/projects/ cmip5/.

Open Access This article is licensed under a Creative Commons Attribution 4.0 International License, which permits use, sharing, adaptation, distribution and reproduction in any medium or format, as long as you give appropriate credit to the original author(s) and the source, provide a link to the Creative Commons licence, and indicate if changes were made. The images or other third party material in this article are included in the article's Creative Commons licence, unless indicated otherwise in a credit line to the material. If material is not included in the article's Creative Commons licence and your intended use is not permitted by statutory regulation or exceeds the permitted use, you will need to obtain permission directly from the copyright holder. To view a copy of this licence, visit http://creativecommonshorg/licenses/by/4.0/.

\section{References}

ABOM (2010) The Wet-Bulb Globe Temperature (WBGT). Australian Bureau of Meteorology http://bom. gov.au/info/thermal_stress

Alexander LV, Zhang X, Peterson TC, Caesar J, Gleason B, Klein Tank AMG, Haylock M, Collins D, Trewin B, Rahimzadeh F, Tagipour A, Rupa Kumar K, Revadekar J, Griffiths G, Vincent L, Stephenson DB, Burn J, Aguilar E, Brunet M, Taylor M, New M, Zhai P, Rusticucci M, Vazquez-Aguirre JL (2006) Global observed changes in daily climate extremes of temperature and precipitation. J Geophys Res 111(D5):D05109. https://doi.org/10.1029/2005JD006290

Bowler K (2005) Acclimation, heat shock and hardening. J Therm Biol 30(2):125-130. https://doi.org/10. 1016/j.jtherbio.2004.09.001

Brouillet A, Joussaume S (2019) Investigating the Role of the Relative Humidity in the Co-Occurrence of Temperature and Heat Stress Extremes in CMIP5 Projections. Geophysical Research Letters, p 2019GL084156. https://doi.org/10.1029/2019GL084156

Buzan JR, Oleson K, Huber M (2015) Implementation and comparison of a suite of heat stress metrics within the Community Land Model version 4.5. Geosci Model Dev 8(2):151-170. https://doi.org/10.5194/gmd-8-151-2015

Byrne MP, O'Gorman PA (2013) Link between land-ocean warming contrast and surface relative humidities in simulations with coupled climate models: WARMING CONTRAST AND RELATIVE HUMIDITIES. Geophys Res Lett 40(19):5223-5227. https://doi.org/10.1002/grl.50971

Byrne MP, O'Gorman PA (2016) Understanding decreases in land relative humidity with global warming: conceptual model and GCM simulations. J Clim 29(24):9045-9061. https://doi.org/10.1175/JCLI-D$16-0351.1$

Chavaillaz Y, Joussaume S, Dehecq A, Braconnot P, Vautard R (2016) Investigating the pace of temperature change and its implications over the twenty-first century. Clim Chang 137(1-2):187-200. https://doi.org/10.1007/s10584-016-1659-4 
Chen Y, Moufouma-Okia W, Masson-Delmotte V, Zhai P, Pirani A (2018) Recent progress and emerging topics on weather and climate extremes since the fifth assessment report of the intergovernmental panel on climate change. Annu Rev Environ Resour 43(1):35-59. https://doi.org/10.1146/annurev-environ102017-030052

Coffel ED, Horton RM, de Sherbinin A (2018) Temperature and humidity based projections of a rapid rise in global heat stress exposure during the 21st century. Environ Res Lett 13(1):014001. https://doi.org/10.1088/1748-9326/aaa00e

Coffel ED, Horton RM, Winter JM, Mankin JS (2019) Nonlinear increases in extreme temperatures paradoxically dampen increases in extreme humid-heat. Environ Res Lett 14(8):084003. https://doi.org/10.1088/1748-9326/ab28b7

Collins M, Knutti R, Arblaster J, Dufresne JL, Fichefet T, Friedlingstein P, Gao X, Gutowski W, Johns T, Krinner G, Shongwe M, Tebaldi C, Weaver A, Wehner M (2013) Long-term Climate change: Projections, Commitments and Irreversibility, Cambridge University Press, Cambridge, UK and New York, USA, chap 12, p 1029-1136. https://doi.org/10.1017/CBO9781107415324.024

Cusack M, Alastuey A, Pérez N, Pey J, Querol X (2012) Trends of particulate matter ( $\left.\mathrm{PM}_{2.5}\right)$ and chemical composition at a regional background site in the Western Mediterranean over the last nine years (20022010). Atmos Chem Phys 12(18):8341-8357. https://doi.org/10.5194/acp-12-8341-2012

Davies-Jones R (2008) An efficient and accurate method for computing the wet-Bulb temperature along pseudoadiabats. Mon Weather Rev 136(7):2764-2785. https://doi.org/10.1175/2007MWR2224.1

Dee DP, Uppala SM, Simmons AJ, Berrisford P, Poli P, Kobayashi S, Andrae U, Balmaseda MA, Balsamo G, Bauer P, Bechtold P, Beljaars ACM, van de Berg L, Bidlot J, Bormann N, Delsol C, Dragani R, Fuentes M, Geer AJ, Haimberger L, Healy SB, Hersbach H, Hólm EV, Isaksen L, Kållberg P, Köhler M, Matricardi M, McNally AP, Monge-Sanz BM, Morcrette JJ, Park BK, Peubey C, de Rosnay P, Tavolato C, Thépaut JN, Vitart F (2011) The ERA-Interim reanalysis: configuration and performance of the data assimilation system. Q J R Meteorol Soc 137(656):553-597. https://doi.org/10.1002/qj.828

Diffenbaugh NS, Pal JS, Giorgi F, Gao X (2007) Heat stress intensification in the Mediterranean climate change hotspot. Geophys Res Lett 34(11). https://doi.org/10.1029/2007GL030000

Donat MG, Pitman AJ, Seneviratne SI (2017) Regional warming of hot extremes accelerated by surface energy fluxes: Accelerated Warming of Hot Extremes. Geophys Res Lett 44(13):7011-7019. https://doi.org/10.1002/2017GL073733

Dunne JP, Stouffer RJ, John JG (2013) Reductions in labour capacity from heat stress under climate warming. Nat Clim Chang 3(6):563-566. https://doi.org/10.1038/nclimate1827

Fischer EM, Knutti R (2013) Robust projections of combined humidity and temperature extremes. Nat Clim Chang 3(2):126-130. https://doi.org/10.1038/nclimate1682

Fischer EM, Oleson KW, Lawrence DM (2012) Contrasting urban and rural heat stress responses to climate change. Geophys Res Lett 39(3):L03705. https://doi.org/10.1029/2011GL050576

Flato G, Marotzke J, Abiodun B, Braconnot P, Chou S, Collins W, Cox P, Driouech F, Emori S, Eyring V, Forest C, Gleckler P, Guilyardi E, Jakob C, Kattsov V, Reason C, Rummukainen M (2013) Evaluation of climate models, Cambridge University press, Cambridge, UK and New York, book section 9, p 741-866. https://doi.org/10.1017/CBO9781107415324.020

Freychet N, Tett S, Yan Z, Li Z (2020) Underestimated change of wet-Bulb temperatures over east and south china. Geophys Res Lett 47(3). https://doi.org/10.1029/2019GL086140

Galloway S, Maughan R (1997) Effects of ambient temperature on the capacity to perform prolonged cycle exercise in man. Med Sci Sports Exerc 29(9):1240-1249

Good P, Lowe JA, Collins M, Moufouma-Okia W (2008) An objective tropical Atlantic sea surface temperature gradient index for studies of south Amazon dry-season climate variability and change. Philosophical Transactions of the Royal Society B:, Biological Sciences 363(1498):1761-1766. https://doi.org/10.1098/rstb.2007.0024

Grundstein A, Cooper E (2018) Assessment of the Australian Bureau of Meteorology wet bulb globe temperature model using weather station data. Int J Biometeorol 62(12):2205-2213. https://doi.org/10.1007/s00484-018-1624-1

Hansen J, Sato M, Ruedy R (2012) Perception of climate change. Proceedings of the National Academy of Sciences 109(37):E2415-E2423. https://doi.org/10.1073/pnas.1205276109

Hartmann D, Klein Tank A, Rusticucci M, Alexander L, Bronnimann S, Charabi Y, Dentener F, Dlugokencky E, Easterling D, Kaplan A, Soden B, Thorne P, Wild M, Zhai P (2013) Observations: Atmosphere and Surface, Cambridge University Press, Cambridge, UK and New York, book section 2, p 159-254. https://doi.org/10.1017/CBO9781107415324.008

Hirschi M, Seneviratne SI, Alexandrov V, Boberg F, Boroneant C, Christensen OB, Formayer H, Orlowsky B, Stepanek P (2011) Observational evidence for soil-moisture impact on hot extremes in southeastern Europe. Nat Geosci 4(1):17-21. https://doi.org/10.1038/ngeo1032 
Horton RM, Mankin JS, Lesk C, Coffel E, Raymond C (2016) A Review of Recent Advances in Research on Extreme Heat Events. Current Climate Change Reports. https://doi.org/10.1007/s40641-016-0042-X

Jones B, O’Neill BC (2016) Spatially explicit global population scenarios consistent with the Shared Socioeconomic Pathways. Environ Res Lett 11(8):084003. https://doi.org/10.1088/1748-9326/11/8/084003

Kjellstrom T, Holmer I, Lemke B (2009) Workplace heat stress, health and productivity - an increasing challenge for low and middle-income countries during climate change. Global Health Action 2(1):2047. https://doi.org/10.3402/gha.v2i0.2047

Kjellstrom T, Briggs D, Freyberg C, Lemke B, Otto M, Hyatt O (2016) Heat, human performance, and occupational health: a key issue for the assessment of global climate change impacts. Annu Rev Public Health 37(1):97-112. https://doi.org/10.1146/annurev-publhealth-032315-021740

Klein R, Midgley G, Preston B, Alam M, Berkhout F, Dow K, Shaw M (2014) Adaptation opportunities, constraints, and limitss, Cambridge University Press, Cambridge, UK and New York, USA, book section 16, p 899-943

Knutti R, Masson D, Gettelman A (2013) Climate model genealogy: Generation CMIP5 and how we got there. Geophys Res Lett 40(6):1194-1199. https://doi.org/10.1002/grl.50256

Kunreuther H, Heal G, Allen M, Edenhofer O, Field CB, Yohe G (2013) Risk management and climate change. Nat Clim Chang 3(5):447-450. https://doi.org/10.1038/nclimate1740

Leiserowitz A (2006) Climate change risk perception and policy preferences: the role of affect, imagery, and values. Clim Chang 77(1-2):45-72. https://doi.org/10.1007/s10584-006-9059-9

Li J, Chen YD, Gan TY, Lau NC (2018) Elevated increases in human-perceived temperature under climate warming. Nat Clim Chang 8(1):43-47. https://doi.org/10.1038/s41558-017-0036-2

Liebmann B, Dole RM, Jones C, Bladé I, Allured D (2010) Influence of choice of time period on global surface temperature trend estimates. Bull Am Meteorol Soc 91(11):1485-1492. https://doi.org/10.1175/2010BAMS3030.1

Liljegren JC, Carhart RA, Lawday P, Tschopp S, Sharp R (2008) Modeling the wet bulb globe temperature using standard meteorological measurements. J Occup Environ Hyg 5(10):645-655. https://doi.org/10.1080/15459620802310770

Marengo JA, Espinoza JC (2016) Extreme seasonal droughts and floods in amazonia: causes, trends and impacts: Extremes in amazonia. Int J Climatol 36(3):1033-1050. https://doi.org/10.1002/joc.4420

Masterton J, Richardson F (1979) Humidex: a Method of Quantifying Human Discomfort due to Excessive Heat and Humidity. Atmospheric Environment Service, Canada, p 45

Matthews TKR, Wilby RL, Murphy C (2017) Communicating the deadly consequences of global warming for human heat stress. Proceedings of the National Academy of Sciences 114(15):3861-3866. https://doi.org/10.1073/pnas.1617526114

Meehl GA (2004) More intense, more frequent, and longer lasting heat waves in the 21st Century. Science 305(5686):994-997. https://doi.org/10.1126/science.1098704

Moore FC, Obradovich N, Lehner F, Baylis P (2019) Rapidly declining remarkability of temperature anomalies may obscure public perception of climate change. In: Proceedings of the National Academy of Sciences, pp 201816541. https://doi.org/10.1073/pnas.1816541116

Mora C, Dousset B, Caldwell IR, Powell FE, Geronimo RC, Bielecki C, Counsell CWW, Dietrich BS, Johnston ET, Louis LV, Lucas MP, McKenzie MM, Shea AG, Tseng H, Giambelluca TW, Leon LR, Hawkins E, Trauernicht C (2017) Global risk of deadly heat. Nat Clim Chang 7(7):501-506. https://doi.org/10.1038/nclimate3322

Mora C, Spirandelli D, Franklin EC, Lynham J, Kantar MB, Miles W, Smith CZ, Freel K, Moy J, Louis LV, Barba EW, Bettinger K, Frazier AG, Colburn IXJF, Hanasaki N, Hawkins E, Hirabayashi Y, Knorr W, Little CM, Emanuel K, Sheffield J, Patz JA, Hunter CL (2018) Broad threat to humanity from cumulative climate hazards intensified by greenhouse gas emissions. Nat Clim Chang 8(12):1062-1071. https://doi.org/10.1038/s41558-018-0315-6

O’Connor RE, Bard RJ, Fisher A (1999) Risk perceptions, general environmental beliefs, and willingness to address climate change. Risk Anal 19(3):461-471. https://doi.org/10.1111/j.1539-6924.1999.tb00421.x

Oleson KW, Monaghan A, Wilhelmi O, Barlage M, Brunsell N, Feddema J, Hu L, Steinhoff DF (2015) Interactions between urbanization, heat stress, and climate change. Clim Chang 129(3-4):525-541. https://doi.org/10.1007/s10584-013-0936-8

Orlowsky B, Seneviratne SI (2012) Global changes in extreme events: regional and seasonal dimension. Clim Chang 110(3-4):669-696. https://doi.org/10.1007/s10584-011-0122-9

Reser JP, Morrissey SA, Ellul M (2011) The threat of climate change: psychological response, adaptation, and impacts. In: Weissbecker I (ed) Climate Change and Human Well-Being: Global Challenges and Opportunities. Springer, New York, pp 19-42. https://doi.org/10.1007/978-1-4419-9742-5_2

Riahi K, van Vuuren DP, Kriegler E, Edmonds J, O’Neill BC, Fujimori S, Bauer N, Calvin K, Dellink R, Fricko O, Lutz W, Popp A, Cuaresma JC, Kc S, Leimbach M, Jiang L, Kram T, Rao S, Emmerling 
J, Ebi K, Hasegawa T, Havlik P, Humpenöder F, Da Silva LA, Smith S, Stehfest E, Bosetti V, Eom J, Gernaat D, Masui T, Rogelj J, Strefler J, Drouet L, Krey V, Luderer G, Harmsen M, Takahashi K, Baumstark L, Doelman JC, Kainuma M, Klimont Z, Marangoni G, Lotze-Campen H, Obersteiner M, Tabeau A, Tavoni M (2017) The Shared Socioeconomic Pathways and their energy, land use, and greenhouse gas emissions implications: An overview. Glob Environ Chang 42:153-168. https://doi.org/10.1016/j.gloenvcha.2016.05.009

Scoccimarro E, Fogli PG, Gualdi S (2017) The role of humidity in determining scenarios of perceived temperature extremes in Europe. Environ Res Lett 12(11):114029. https://doi.org/10.1088/1748-9326/aa8cdd

Seneviratne SI, Lüthi D, Litschi M, Schär C (2006) Land-atmosphere coupling and climate change in Europe. Nature 443(7108):205-209. https://doi.org/10.1038/nature05095

Seneviratne SI, Wartenburger R, Guillod BP, Hirsch AL, Vogel MM, Brovkin V, van Vuuren DP, Schaller N, Boysen L, Calvin KV, Doelman J, Greve P, Havlik P, Humpenöder F, Krisztin T, Mitchell D, Popp A, Riahi K, Rogelj J, Schleussner CF, Sillmann J, Stehfest E (2018) Climate extremes, land-climate feedbacks and land-use forcing at 1.5c. Philosophical Transactions of the Royal Society a: Mathematical, Physical and Engineering Sciences 376(2119):20160450. https://doi.org/10.1098/rsta.2016.0450

Settele J, Scholes R, Betts SR, Leadley P, Nepstad D, Overpeck J, Taboada M (2014) Terrestrial and Inland Water Systems. Cambridge University Press, Cambridge, UK and New York, book section 4, p 271-359. https://doi.org/10.1017/CBO9781107415324.004

Simonet G (2015) Une brève histoire de l'adaptation : l'évolution conceptuelle au fil des rapports du GIEC (1990-2014). Natures Sciences Sociétés 23:S52-S64. https://doi.org/10.1051/nss/2015018

Steadman R (1984) A universal scale of apparent temperature. Canada:, Atmospheric Environment Service 23(87): 1674

Szopa S, Balkanski Y, Schulz M, Bekki S, Cugnet D, Fortems-Cheiney A, Turquety S, Cozic A, Déandreis C, Hauglustaine D, Idelkadi A, Lathière J, Lefevre F, Marchand M, Vuolo R, Yan N, Dufresne JL (2013) Aerosol and ozone changes as forcing for climate evolution between 1850 and 2100. Clim Dyn 40(910):2223-2250. https://doi.org/10.1007/s00382-012-1408-y

Taylor KE, Stouffer RJ, Meehl GA (2012) An overview of CMIP5 and the experiment design. Bull Am Meteorol Soc 93(4):485-498. https://doi.org/10.1175/BAMS-D-11-00094.1

Vogel MM, Orth R, Cheruy F, Hagemann S, Lorenz R, Hurk BJJM, Seneviratne SI (2017) Regional amplification of projected changes in extreme temperatures strongly controlled by soil moisture-temperature feedbacks. Geophys Res Lett 44(3):1511-1519. https://doi.org/10.1002/2016GL071235

van Vuuren DP, Edmonds J, Kainuma M, Riahi K, Thomson A, Hibbard K, Hurtt GC, Kram T, Krey V, Lamarque JF, Masui T, Meinshausen M, Nakicenovic N, Smith SJ, Rose SK (2011) The representative concentration pathways: an overview. Clim Chang 109(1-2):5-31. https://doi.org/10.1007/s10584-011-0148-Z

Weedon GP, Gomes S, Viterbo P, Shuttleworth WJ, Blyth E, Österle H, Adam JC, Bellouin N, Boucher O, Best M (2011) Creation of the WATCH forcing data and its use to assess global and regional reference crop evaporation over land during the twentieth century. J Hydrometeorol 12(5):823-848. https://doi.org/10.1175/2011JHM1369.1

Weedon GP, Balsamo G, Bellouin N, Gomes S, Best MJ, Viterbo P (2014) The WFDEI meteorological forcing data set: WATCH Forcing Data methodology applied to ERA-Interim reanalysis data. Water Resour Res 50(9):7505-7514. https://doi.org/10.1002/2014WR015638

World Bank (2013) Turn down the heat: Climate extremes, regional impacts, and the case for resilience. A report for the World Bank by the Potsdam Institute for Climate Impact Research and Climate Analytics

Yaglou CP, Minard D (1957) Control of heat casualties at militarytraining centers. American Medical Association Archives of Industrial Health 16:302-316

Zhao Y, Ducharne A, Sultan B, Braconnot P, Vautard R (2015) Estimating heat stress from climate-based indicators: present-day biases and future spreads in the CMIP5 global climate model ensemble. Environ Res Lett 10(8):084013. https://doi.org/10.1088/1748-9326/10/8/084013

Publisher's note Springer Nature remains neutral with regard to jurisdictional claims in published maps and institutional affiliations. 